\title{
ARTICULACIÓN TERRITORIAL DE LOS ESPACIOS DE REALENGO EN EL ÁREA SEPTENTRIONAL CANTÁBRICA DEL REINO DE CASTILLA EN LA MODERNIDAD ${ }^{* 1}$
}

\author{
TERRITORIAL ARTICULATION OF REALENGO SPACES IN THE \\ NORTHERN CANTABRIAN AREA OF THE KINGDOM OF CASTILLA \\ IN MODERNITY
}

\author{
ARTICULAÇÃO TERRITORIAL DOS ESPAÇOS DE REALENGO NA ZONA \\ NORTE DE CANTABRIAN DO REINO DE CASTILLA \\ NA MODERNIDADE
}

\author{
OSVALDO VÍCTOR PEREYRA** \\ Universidad Nacional de La Plata \\ https://doi.org/10.46553/EHE.23.2.2021.p104-120
}

\begin{abstract}
Resumen
El proceso de articulación territorial en los territorios históricos de Cantabria hacia los siglos XV$\mathrm{XVI}$, es el centro de análisis del presente trabajo. Para ello tomamos en consideración las diferentes dinámicas de organización y hermanamiento que, desde la Edad Media, operan para la organización de los diversos espacios locales -barrios y concejos- en las distintas instancias intermedias que permiten estructurar los llamados corregimientos. A partir de un estudio de caso: el llamado Corregimiento de las Cuatro Villas de la Costa de la Mar, podemos establecer el complejo proceso de organización territorial y político que define estos espacios jurisdiccionales múltiples y complejos.
\end{abstract}

Palabras clave

Corregimiento, concejos, juntas, hermanamiento, jurisdicción

\section{Summary}

The process of territorial articulation in the historical territories of Cantabria towards the XV-XVI centuries, is the center of analysis of the present work. For it we take into consideration the different dynamics of organization and twinning that, since the Middle Ages, operate for the organization of the various local spaces -barrios and councils- in the different intermediate instances that allow structuring the so-called corregimientos. From a case study: so-called Corregimiento de las Cuatro Villas of the Costa de la Mar, we can establish the complex process of territorial and political organization that defines these multiple and complex jurisdictional spaces.

\footnotetext{
* Fecha de recepción: 17/08/2020. Fecha de aceptación: 03/12/2020.

**Doctor en Historia y docente categorizado por la Universidad Nacional de La Plata, ORCID: https://orcid.org/0000-0001-6206-7575. Departamento de Historia, Facultad de Humanidades y Ciencias de la Educación, Calle 51 e/ 124 y 125, B1925ASA, Ensenada, Buenos Aires, Argentina, vopereyra@gmail.com

${ }^{1}$ This work is an output of the Resistance Project, which has received funding from the European Union's Horizon 2020 research and innovation programme under the Marie Skłodowska-Curie grant agreement No 778076.
} 


\section{Keywords}

Corregimiento, councils, boards, twinning, jurisdiction

\section{Resumo}

O processo de articulação territorial nos territórios históricos da Cantábria os séculos XV-XVI, é o centro de análise do presente trabalho. Para isso, levamos em consideração as diferentes dinâmicas de organização e geminação que, desde a Idade Média, operam para a organização dos diversos espaços locais - bairros e conselhos - nas diferentes instâncias intermediárias que permitem estruturar os chamados corregimientos. A partir de um estudo de caso: o chamado Corregimiento de las Cuatro Villas da Costa de la Mar, podemos estabelecer o complexo processo de organização territorial e política que define esses múltiplos e complexos espaços jurisdicionais.

Palavras chave: corregimiento - conselhos - juntas - geminação - jurisdição

\section{Introducción}

Hablar de articulación territorial y de administración del espacio en el Antiguo Régimen es adentrarnos en un mundo plural y abigarrado, un conjunto complejo de adscripciones jurídico-administrativas que se van agregando, reensamblando y evolucionando desde la Edad Media a la modernidad. El resultado, un espacio laberíntico de entes jurisdiccionales de diversos tamaños y formalizaciones que engloban los unos a los otros y que -en la práctica concreta del ejercicio administrativo y de gobierno- muchas veces se superponen y entran en colisión entre sí. ${ }^{2}$ Con el fin de demostrar y analizar dicha complejidad institucional, este trabajo centra su análisis en la organización del llamado Corregimiento de las Cuatro Villas de la Costa de la Mar (1475-1778) que incorporaba bajo su égida todo el territorio de realengo de Cantabria ${ }^{3}$ durante del siglo XV.

Para hacer comprensible este complejo entramado jurisdiccional debemos decir que, en los espacios cántabros, la forma más elemental que integra las antiguas demarcaciones que se van ensamblando unas a otras desde la Edad Media son los llamados barrios -mínimas unidades de adscripción- que se vertebran a su vez en los concejos -los cuales aglutinan uno o varios núcleos poblacionales, tanto en el espacio rural como en las villas- y que, a su vez, se irán agrupando en entidades de mayor rango. ${ }^{4}$ Por ejemplo, en el territorio del interior rural tenemos los llamados valles -entidades con indudables raíces medievales- que terminarán organizándose colectivamente en las llamadas Juntas o Hermandades. ${ }^{5}$

\footnotetext{
${ }^{2}$ Véase como estado de la cuestión general del problema de la articulación territorial peninsular REY CASTELAO, 2012, 77-96.

${ }^{3}$ Debemos tener en cuenta que el realengo representaba, aproximadamente, el $60 \%$ del territorio histórico de la actual Cantabria, el restante $40 \%$ se encontraba bajo el poder de distintos señores, lo cual complejiza el problema de la estructuración administrativa y política del conjunto territorial. Véase RODRÍGUEZ FERNÁNDEZ, 1986.

${ }^{4}$ Utilizando la conceptualización definida por GARCÍA DE CORTAZAR, 2002, 13-46, podemos hablar, según aparece en la página 41, "de células de encuadramiento socio-territorial (...) la estabilidad del marco físico de esas unidades se combinó normalmente con situaciones de discontinuidad de los titulares del poder".

${ }^{5}$ En general, cuando hablamos del origen bajomedieval del hermanamiento de poblaciones, se nos compone su erección a momentos de vacío de poder con una existencia más bien coyuntural y transitoria, condiciones diferentes a las que encontramos cuando estudiamos aquellas agrupaciones que, en la alta-modernidad, conocemos con la denominación de Juntas. Ello es lo que aleja a algunos medievalistas vizcaínos como Díez de Salazar y Rosa Ayerbe de pensar algún tipo de relación de continuidad entre el proceso de generación de las Hermandades bajomedievales castellanas y el origen del proceso de generación de las
} 
Hacia el siglo XVI, dichas adscripciones jurisdiccionales menores se encuentran engarzadas en cinco grandes demarcaciones intermedias llamadas Juntas Generales o de Provincia, conformando así las denominadas: 1- Junta de la Provincia de los Nueve Valles, 2- la Junta de las Cuatro Villas de la Costa de la Mar de Cantabria, 3- la Junta de la Merindad de Trasmiera, 4- la Junta de la Merindad de Campoo y, finalmente, 5- la Junta de la Provincia de Liébana. Estas unidades jurisdiccionales generales sobreviven como espacios intermedios de organización y administración que a su vez se hallaban englobados al interior de otros cinco grandes corregimientos cuya titularidad terminará repartiéndose entre el Rey y los grandes señores: 1- el Corregimiento de las Cuatro Villas de la Costa de la Mar -centro de nuestro análisis-, 2- el de la Merindad de Campoo, 3- el de la Provincia de Liébana, 4- el del Mayordomado de la Vega, y 5- el de Soba, Ruesga y Villaverde. En cuanto a la titularidad de los mismos, los dos primeros dependían directamente de la corona, los otros tres estaban bajo la dependencia jurisdiccional de los titulares de distintos estados señoriales de la alta nobleza castellana: el de Liébana y Mayordomado de la Vega -dependientes de la Casa de los Mendoza, duques del Infantado- y el de los valles de Soba, Ruesga y Villaverde -dependientes de la Casa de los Velasco, Condestables hereditarios del Reino de Castilla- eran, sin duda, los más destacados por su extensión territorial. ${ }^{6}$

\section{La construcción agregativa de un espacio jurisdiccional y la expansión de la justicia del rey: el Corregimiento de las Cuatro Villas de la Costa de la Mar (1475- 1778)}

El núcleo central de este corregimiento se encuentra conformado por los espacios poblacionales nacidos al calor de la política fundacional de villas portuarias impulsada por la monarquía castellana. Al dividirse el reino Castellanoleonés en 1157, se inicia en Castilla el proceso de fundación de villas bajo el reinado de Alfonso VIII. Surgen así las llamadas villas marítimas de Castro Urdiales en 1163 (¿1173?), Santander en 1187, Laredo en 1200 y San Vicente de la Barquera en $1210 .^{7}$

Los fueros de las villas de la costa de la mar de Castilla proceden de los denominados fueros de francos que pueden dividirse en tres grandes familias forales: las de los fueros de Logroño, de Sahagún y de San Sebastián, marcando claramente que la fundación de dichas villas responde a una política deliberada por parte del rey Alfonso VIII ${ }^{8}$ de atraer

\footnotetext{
Juntas en Vizcaya. Véase DIÉZ DE SALAZAR y FERNÁNDEZ y AYERBE SALAZAR, 1990. Más allá de las interpretaciones del caso, para nosotros lo importante de remarcar es la dinámica de la formación medieval de estas formas adscriptivas amplias.

${ }^{6}$ Existían demarcaciones menores que escapaban a la adscripción en los corregimientos, encontrándose las mismas bajo la jurisdicción de distintos señores laicos y religiosos: es el caso del Marquesado de Argüeso (duques del Infantado), del Condado de Castañeda (marqueses de Aguilar), de la villa de Pesquera (Arzobispo de Burgos); así como de jurisdicción compartida como el caso de la villa de Tresviso, entre los Duques del Infantado y el Abad de Santillana.

7 Contamos con una cantidad de documentación édita de estas villas marítimas y sus conflictos jurisdiccionales durante la Baja Edad Media: CUÑAT CISCAR, 1998; SOLÓRZANO TELECHEA y FERNÁNDEZ GONZÁLEZ, 1996; SOLÓRZANO TELECHEA, 1995; SOLÓRZANO TELECHEA, 1998; SOLÓRZANO TELECHEA, 1999a; SOLÓRZANO TELECHEA, 1999b; SOLÓRZANO TELECHEA, et al. 2004; BLANCO CAMPOS, 1996; BARÓ PAZOS y SERNA VALLEJO, 2001; BARÓ PAZOS y GALVÁN RIVERO, 2006; SERNA VALLEJO, 2018; entre otros títulos.

${ }^{8}$ La política de fundación de estas villas marítimas se debe al interés de Alfonso VIII, de brindar una más efectiva protección de la frontera costera septentrional en previsión de ataques por parte de los reinos vecinos de León o de Navarra, así como bases seguras para el comercio e intercambio con Inglaterra, a partir de la consolidación de la alianza política con la casa Plantagenet. Véanse los trabajos al respecto de CERDA, 2012, 629-652; WALKER, 2007, 67-87.
} 
pobladores foráneos a la costa de Cantabria, tal vez gascones, como ocurre en el caso de Santander durante el siglo XIII. Con el otorgamiento de las cartas forales, estas villas nuevas tomarán el relevo a los monasterios en el control y articulación de este espacio territorial. ${ }^{9}$ Debemos hablar de un particular proceso de urbanización septentrional que se encuentra inscripto dentro de la dinámica de ascensión y reordenamiento de los poderes feudales, tanto locales, como comarcales y regionales. ${ }^{10}$

De esta manera, la fundación de las villas de la costa de la mar trae consigo una transferencia del poder de dominio señorial eclesiástico al concilium (concejo urbano), posibilitando así el ascenso de incipientes oligarquías concejiles que asentarán las bases para proyectar su poder sobre el territorio circundante que -por virtud de estas cartas forales- termina siendo subordinado económica y jurídicamente a las villas. Un espacio jurisdiccional amplio que no solo integraba el territorio, sino que, al mismo tiempo, expandía su control sobre el espacio marítimo circundante. ${ }^{11}$

Hasta ese momento, las relaciones de los diferentes núcleos de población de estos territorios con la monarquía se habían desarrollado mediadas por la presencia de fuertes asentamientos eclesiásticos y de la nobleza que actuaban articulando las relaciones de los distintos grupos de aldeas inscriptos en los diferentes valles. A partir de entonces la presencia de las villas con fuero permitirá una nueva jerarquización.

Este proceso de articulación territorial no estuvo exento de conflictos y resistencias por parte de las circunscripciones incorporadas al asentamiento definitivo de estas nuevas realidades jurisdiccionales, ya que, gracias a los fueros, las villas pasaron a obtener el control de los espacios de producción que hasta entonces eran propios de las aldeas. De la misma manera, dicha fijación de los límites estuvo jalonada por conflictos de diversa intensidad con la expansión de los poderosos señores territoriales. ${ }^{12}$ Tenemos así un doble foco de problemas: endógenos y exógenos, y el origen de estos conflictos tiende a ser principalmente económico, en torno al aprovechamiento de los recursos de los distintos espacios. A lo largo de los siglos XIII y XV, podemos afirmar que se va consolidando lentamente las áreas jurisdiccionales de las villas a partir del fortalecimiento de estas como nodos comerciales. ${ }^{13}$

Hacia el último tercio del siglo XV, los Reyes Católicos impusieron la figura del corregidor $^{14}$ sobre dichos territorios jurisdiccionales abarcando así las administraciones

\footnotetext{
${ }^{9}$ Véase PEÑA BOCOS, 1989, 97-111.

${ }^{10}$ Simplemente como ejemplo, como consta en el Fuero de San Vicente de la Barquera (1210). Véase MARTÍNEZ DÍEZ, 1976, 527-608, 599, apéndice II, "Do etiam uobis la Barquera cum toto suo termino, et cum ómnibus pertinentiis suis." Como consta, estos espacios no estaban despoblados, y el esfuerzo unificador de la corona condiciona la rearticulación del espacio encabezado jurisdiccionalmente por la villa. ${ }^{11}$ Siguiendo con el ejemplo de San Vicente de la Barquera, su dominio exclusivo de las aguas se encontraba comprendido entre la desembocadura del río Deva, en Tina Mayor, hasta la Punta Ballota, cerca de Suances. Estas delimitaciones dilatadas generaban continuos conflictos jurisdiccionales durante la Edad Media, interviniendo permanentemente la corona en la protección de estos espacios. Véase BLANCO CAMPOS, 2005, doc. 136, año 1502. Para un desarrollo general del problema de la conflictividad jurisdiccional del espacio marítimo véase ARIZAGA BOLUMBURU, 2005, 17-55.

${ }_{12}$ Existe una extensa bibliografía en torno a la conflictividad en el espacio cantábrico: PÉREZ BUSTAMANTE, 1975, 1-60; SAINZ DÍAZ, 1986; FRANCO SILVA, 1989, 225-284; SOLÓRZANO TELECHEA y FERNÁNDEZ GONZÁLEZ, 1996.; RODRÍGUEZ FERNÁNDEZ, 2001, 265-322; SOLÓRZANO TELECHEA, 2002; BARÓ PAZOS, 2010; VITORIA, 2006, 9-24; SOLÓRZANO TELECHEA, 2011-2012, 735-750; entre otros.

${ }^{13}$ MONSALVO ANTÓN, 2000-2002, 157-202. En términos de su comparación con otros espacios es importantes establecer paralelos con los desarrollos de redes comerciales de ciudades en territorios como los Países Bajos, Inglaterra, Francia y Portugal -la fachada noratlántica- resulta interesante en ese caso las obras de STABEL, 1997 y MURRAY, 2009, entre otras.

${ }^{14}$ Sobre el desarrollo de la institución en época bajomedieval véase GONZÁLEZ ALONSO, 1970; BERMÚDEZ AZNAR, 1979; FORTEA PÉREZ, 2000, 261-308.
} 
de las distintas villas y lugares. En el año de 1475, se crea así el llamado corregimiento de las Cuatro Villas de la Costa de la Mar. ${ }^{15}$ Indudablemente este hecho acentuaba la intervención de la corona en la vida política de los distintos núcleos poblacionales bajo su mando, que encontraba en dicha figura la presencia efectiva del poder real.

En cuanto a la amplitud de ese territorio, en teoría, el corregidor de la Cuatro Villas de las Costa de la Mar tenía bajo su égida todo el territorio de realengo de Cantabria, desde los valles de Peñamellera y Ribadedeva, al oeste, hasta el propio término encabezado por la villa de Castro Urdiales al este, abarcando, al sur, hasta el límite con la Merindad de Campoo. En su interior se encontraban involucradas las administraciones locales y supra-concejiles que conformaban este vasto territorio. Para sintetizar el problema, el nombramiento por parte del corregidor de los distintos alcaldes mayores en las diferentes circunscripciones locales mediatizó el tradicional ejercicio de la justicia ejercido por la antigua figura de los alcaldes ordinarios o de fuero desde el interior mismo de los gobiernos locales. A través de este condensado esquema, el poder del corregidor se capilarizó hasta alcanzar los distintos núcleos poblacionales (de diversos tamaños y tipos) que se encontraban inscriptos al interior de estas demarcaciones territoriales de enorme complejidad, designadas como corregimientos. (véase cuadro 1).

${ }^{15}$ El primer corregidor fue Hurtado de Luna, quien encontró la férrea resistencia de los sectores urbanos privilegiados de San Vicente de la Barquera. Véase SOLÓRZANO TELECHEA, 2004, 16-17. 


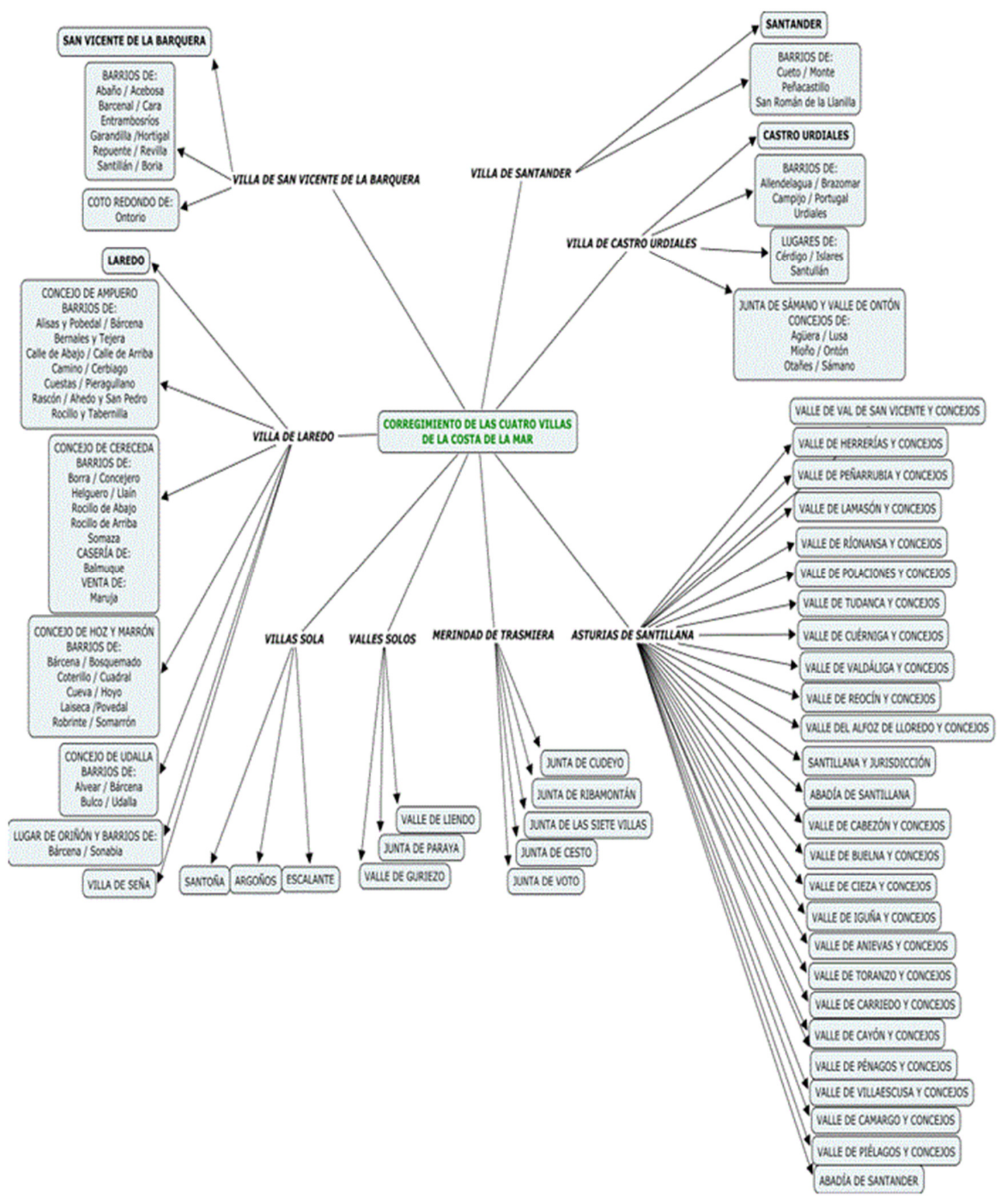

Cuadro 1: Esquema del alcance del Corregimiento de las Cuatro Villas de la Costa de la Mar hasta el nivel desagregado de las administraciones locales. Cuadro de elaboración propia en base a los datos contenidos en RODRÍGUEZ FERNÁNDEZ, 1986.

En la base de esta macroestructura jurisdiccional se hallaban las distintas estructuras locales y, como el órgano más elemental de autogobierno de las diferentes unidades poblacionales encontramos los barrios. Poco es lo que sabemos de la forma primitiva de organización de estos; su demarcación aparece veladamente en la documentación, producto de la asistemática configuración que presentan. Sin embargo, podemos delinearlos esquemáticamente como agrupamientos humanos primarios, determinados 
por la vecindad, ${ }^{16}$ que configuran cierto ordenamiento administrativo centrado en los conjuntos de familias en función del "(...) bien común de la comunidad”. Ellos tienen su origen, muy probablemente, en aquel proceso organizativo primigenio llevado adelante por el poder monástico (en términos de colaciones, feligresías y, posteriormente, parroquias) que no solo subsistirán en la Edad Moderna, sino que también transmitirán a la esfera de la administración política de dichos territorios, esta arcaica forma organizacional heredada.

Al frente de estos grupos de base encontramos algunos órganos colectivos de gestión mejor definidos, las llamadas juntas de barrio o de colación, organización inicial de las poblaciones que se encontraba constituida por los vecinos de cada barrio convocados a su seno, según la documentación: “(...) al sonido de campana tañida”. Se hallaban presididos por un oficial (que adquiere diversas denominaciones según la comarca o la región, entre ellas mayordomo, procurador y regidor pedáneo). Sea cual fuere aquélla, a este oficio de base le correspondía ser delegado de los regidores del concejo en sus respectivas colaciones. De la unión de estos barrios o colaciones (es decir, siempre de dos o más) se conformaron los concejos, siendo éstos la célula básica en la organización municipal -tanto del mundo rural como del urbano- en Cantabria.

Sin embargo, ambas formas presentan diferencias sustanciales en el caso de extenderse sobre espacios rurales y urbanos, ya que en la administración de los concejos del interior vemos la pertinaz pervivencia de la participación del conjunto de los vecinos en las asambleas abiertas, simplemente por la condición de tales -es decir, como "(...) jefes de familia varones, con casa y hacienda propia"- excluyéndose, por lo tanto, a los solteros menores no emancipados, o que no vivieran en casa propia, y también a las mujeres (casadas o viudas) que carecían de status de autorrepresentación en estas asambleas pues eran representadas por el jefe de la familia (de la misma manera que los menores, ya que de hecho eran consideradas perpetuas menores de edad), así como también de los jornaleros, criados, familiares y demás dependientes. Como sociedad corporativa a todos ellos se los consideraba representados por el cabeza de familia.

En cambio, en los concejos urbanos ${ }^{17}$ la gestión de gobierno y administración se encontraba, ya desde principios de la Edad Moderna, en manos del regimiento o ayuntamiento, los llamados concejos restringidos, los cuales han sido cooptados desde temprano por los linajes de las oligarquías urbanas que se alternan en la elección de los oficios y su representación. Simplificando, los primeros representarían los llamados concejos abiertos que, con mayor o menor amplitud, deben ser vistos como la reunión de los cabezas de familia o jefes de casa o vecinos, lo cual derivada de una concepción paternalista que trasvasa el ámbito doméstico y se proyecta como fuerza organizativa en el político. La casa ${ }^{18}$ y la condición de vecino del cabeza de familia definen así la unidad sintética básica de la organización mínima de las comunidades rurales (igualmente, es necesario destacar aquí que hacia el siglo XVII, en las aldeas más importantes, ya no habría más que una representación restringida). Contrariamente, en los espacios urbanos,

\footnotetext{
${ }^{16}$ Sobre la importancia que adquiere la figura del "vecino" y sus condiciones de formalización al interior de la comunidad véase los trabajos de HERZOG, 2000, 123-131; HERZOG, 2006; CARZOLIO, 2002, 637692; CARZOLIO, 2004, 269-292.

${ }^{17}$ Entre las competencias del gobierno de la ciudad por parte del regimiento está la de establecer ordenanzas -capacidad auto normativa- que tiene su límite en el derecho del Reino. Dicha potestad legislativa del ámbito urbano castellano aparece ya confirmada en las Cortes de Ocaña del año 1422 por el rey Juan II de Castilla: "Ordenamos y mandamos que todas las ciudades, villas y lugares de nuestros Reinos sean gobernados según las ordenanzas y costumbres que tienen de los alcaldes y regidores y oficiales de tales concejos..." Nueva Recopilación. Ley 7, tít. I, Lib. 7.

${ }^{18}$ En relación con la centralidad de la "casa" para el análisis de la organización de las comunidades rurales cántabras véase MANTECÓN MOVELLÁN, 1997.
} 
predomina tempranamente el llamado concejo cerrado o regimiento, que será el órgano de gestión del gobierno y administración de las villas y cuya composición se encontraba en manos de un reducido grupo de oficiales que eran representantes de los linajes más importantes.

Dicha posición de hegemonía derivaba del control que ellos ejercían sobre las riquezas -tierras, ganados, molinos, ferrerías, así como rentas de diversos tipos- de su posición de notables de las villas, así como por su lugar político diferencial frente al resto de sus convecinos -controlando el concejo de la villa- lo que suponía el dominio de los resortes políticos en beneficio personal pero al amparo de una retórica singular centrada en el "bien común (...)"19 de las comunidades, a las que ellos representaban.

Todo este complejo sistema plural de espacios jurisdiccionales locales se hallaba encabezado por la figura del corregidor ${ }^{20} \mathrm{El}$ poder de este deviene de ser representante del rey frente a las poblaciones y los espacios jurisdiccionales a los que ellas se encuentran adscriptas. Sin embargo, dos elementos aparecen como problemáticos en dicha afirmación: por un lado, qué entender por poder real, en segundo lugar, qué entender por su jurisdicción.

Si es representante del rey está claro que, el fundamento último del ejercicio de sus facultades debe comprenderse por la delegación que hace el monarca en la figura de su oficial real. En este sentido, es necesario analizar el principio constitutivo de esa delegación tomando como punto de arranque, el propio poder del monarca. Como afirmaba B. Clavero:

\begin{abstract}
“(...) entre los siglos XV y XVIII es cuando el rey es fundamentalmente juez y la monarquía primordialmente justicia. La idea se expresaba y realizaba entonces técnicamente: la potestad del rey es jurisdiccional; su potestas resulta jurisdictio. El rey lo que tiene no es exactamente poder, sino potestad jurisdiccional, jurisdicción. Y jurisdicción entonces significa lo que la palabra predica: dicción del derecho. Era declaración, desenvolvimiento, aplicación y aseguramiento del derecho, del ius."21
\end{abstract}

Lo jurisdiccional es así, en definitiva, entendido como la esencia del poder político. El rey no estaba por encima del derecho, estaba para asegurarlo y garantizarlo, utilizando como cimiento la imagen lastrada de la Edad Media: el Rey justiciero. ${ }^{22}$ Ahora bien, esta imagen no significaba, en la práctica, que las tareas jurisdiccionales fuesen ejercidas exclusivamente por los tribunales reales o jueces regios. Es claro que al lado de los mismos y partiendo de simétricas premisas se fueron fortaleciendo también espacios jurisdiccionales dependientes de señores (sean estos laicos o eclesiásticos) así como también de municipios que usufructuaban su posición privilegiada, al mismo tiempo que la doctrina avalaba la existencia de la "justicia local" (como principio organizativo de toda comunidad) y establecía que la misma era desempeñada por los jueces elegidos por los propios vecinos (los llamados "alcaldes foreros"). Tenemos así que, como claramente lo ha expuesto B. González Alonso:

“(...) la jurisdicción no radica en un sujeto único -el rey-, sino en distintos órdenes señorial, municipal, etc.-, que la comparten en régimen de connivencia y cubren de paso

\footnotetext{
${ }^{19}$ El "bien común..." y el "buen gobierno de las villas..." se entienden, así como ficciones operativas en el discurso político de la época que dan sentido a la forma y organización de los gobiernos locales.

${ }^{20}$ Véase FORTEA PÉREZ. 2000, op., cit., 263. "Existía, indudablemente, una correspondencia interna entre el gobierno de las ciudades y el del propio reino..."

${ }^{21}$ CLAVERO, 1996, 15.

${ }^{22}$ Véase GARCÍA DE VALDEAVELLANO, 1998, 443. "La idea del Rey justiciero se consideraba en la edad Media como esencial al concepto de Monarquía. El Rey medieval era, sobre todo, un iudex o juez”.
} 
las lagunas que la deficiente organización central era incapaz de colmar por sí sola. La pluralidad jurisdiccional no es sino un supuesto ejemplificador de la heterogénea base de sustentación de la organización política."23

Este complejo entramado se correspondía con el hecho de la existencia de una pluralidad de formaciones de derecho, y la inexistencia, por lo tanto, de un derecho territorial castellano. Los esfuerzos para organizar todo este conjunto, desde mediados del siglo XIII, con las Partidas ${ }^{24}$ de Alfonso X, vienen a definir esa ordenación sobre la base de hacerlos confluir "a todos" sin olvido de ninguno. ${ }^{25}$

Como señalara B. González Alonso, el rey aparece en las Partidas como “(...) señor et cabeza", cuyo señorío se manifiesta en el poder de "(...) escarmentar los malhechores" y "(...) dar su derecho a cada uno en su tierra." En su función de gobernante asume y reúne la condición de caudillo a la de "(...) juez sobre todos los del reino" con quien colabora en el ejercicio de sus atribuciones un conjunto de oficiales que le representan y permanecen vinculados a él a través del poder delegado, deberes de servicio, fidelidad y obediencia. Entre tales oficiales destacan los "(...) jueces: homes bonos puestos para mandar et facer derecho (...)", cuyo nombramiento (como derivación lógica de lo anterior) se arroga el rey con carácter excluyente. ${ }^{26}$

Como vemos, la fuerza expansiva de esta asociación de imágenes compuestas sobre la figura del monarca como: "rey / señor / cabeza / juez" acompaña, al mismo tiempo, el esfuerzo por el reordenamiento mismo del conjunto plural de fuentes de derecho señaladas anteriormente, hecho que se constata desde mediados del siglo XIV, con el Ordenamiento de Alcalá (1348), que regirá en los reinos de León y de Castilla, y por el cual se intentan dejar fijados los derechos que corresponden al rey frente a los espacios jurisdiccionales locales y estamentales. La generación de una esfera privativa del poder real, que se define, en forma amplia, como la "mayoría", no alcanzable, por lo tanto, por otros poderes del reino. En lo referente a la administración misma de justicia se emplea la fórmula de "mayoría de justicia" o "justicia mayor del rey" lo que le permite intervenir en los territorios sujetos a jurisdicción señorial cuando la justicia no esté bien administrada, es decir, como reza el texto: "la mayoría de la justicia que es cumplirla el rey de los señores menores le menguaren." 27

Es decir, el sentido de la "mayoría" no es el de soberanía tal como lo entendemos hoy. Estaba centrado en la figura del rey y sus derechos cuya dejación le haría perder lo más característico de su oficio, es decir, el señorío real. Dicha intervención iba consolidando lentamente un vehículo de fundamental importancia para dar consistencia a todo el sistema, la vía de la alzada a los tribunales del rey como reconocimiento de la

\footnotetext{
23 Sigue siendo de ineludible referencia para entender la dinámica de las justicias locales en relación con la figura del corregidor el trabajo de GONZÁLEZ ALONSO, op. cit., 19-20.

${ }^{24}$ En el texto de las Partidas el rey aparece como "señor et cabeza", y el señorío de este se manifiesta en su capacidad de "escarmentar los malhechores... y dar su derecho a cada uno en su tierra". Partidas, III, 28,1 .

${ }^{25}$ De esta manera el orden jurídico castellano viene a convertirse en la sumatoria de cuerpos jurídicos parciales ya consagrados de: fueros de hidalgos, ciudades y villas, así como leyes regias, a los que habría que sumar las re- traducciones permanentemente, del antiguo derecho romano y, finalmente, el propio derecho canónico.

${ }^{26}$ GONZÁLEZ ALONSO, op. cit., 21.

27 Ordenamiento de Alcalá, XXVII, III, edición Códigos Españoles, 1872, p. 463. El Ordenamiento de Alcalá es un conjunto de leyes de carácter territorial promulgado por Alfonso XI en las Cortes celebradas en Alcalá de Henares, en 1348, en cuya ley primera se establece el orden general de prelación de fuentes jurídicas: "leyes ciertas". Allí se acepta como fuente alternativa por primera vez, las Partidas. Así queda sancionado el siguiente orden de prelación de fuentes jurídicas: 1. Las leyes contenidas en el propio Ordenamiento de Alcalá; 2. El Fuero municipal de cada localidad y 3. Las Partidas.
} 
primacía del Derecho Real en el orden de prelación de fuentes aplicables en el Reino de Castilla.

\section{Del rey "fiscus" a la constitución de un espacio fiscal articulado en torno a las villas}

Otra dimensión fundamental para tener en consideración al momento de analizar la articulación territorial es la capacidad de la monarquía de constituir un espacio fiscal integrado. Como ya había hecho notar Bartolomé Clavero, el monarca castellano es también "fiscus" 28 , es decir que, para la doctrina jurídica de la época, la cualidad fiscal es una regalía, por lo tanto, una facultad política privativa del rey. Actúan así, sobre la ordenación del espacio fiscal castellano, aquellos principios que han permitido establecer la justicia del monarca.

Partimos también de una composición laberíntica que presentaba el hecho de que frente al espacio fiscal privativo del rey encontramos múltiples situaciones de excepcionalidad fiscal, por lo tanto, de lugares solariegos dotados de inmunidades y en donde observamos que el disfrute de las rentas reales se hallaba enajenado por los titulares de estos. Según M. A. Solinís Estallo ${ }^{29}$, podemos establecer que hacia finales del siglo XV (momento en el cual aparecen ligadas "tercias"30, "salines"31 y "alcabalas") se procede a la delimitación del espacio fiscal real frente al señorial. Entre los años de 14951504, se procede a establecer los llamados encabezamientos, es decir, pactos de carácter público entre la Corona y los concejos de las villas para que sean ellas la que controlen un espacio fiscal. Con el sistema de encabezamiento tenemos la afirmación de las villas marítimas como "cabezas" recaudatorias ${ }^{32}$ Como vemos, es hacia fines del siglo XV, cuando podemos observar que se cristaliza una circunscripción fiscal de la monarquía conformando así un "patrimonium publicum" y trasladando -de esta forma- al plano fiscal la tradicional vinculación que existía entre las villas marítimas cántabras con el tráfico mercantil marítimo y la práctica impositiva. Es importante señalar que la configuración del espacio fiscal del "partido de las Cuatro Villas" queda definida al interior del "corregimiento de las Cuatro Villas de la costa de la Mar". En este sentido lo jurisdiccional precederá en todo momento a lo fiscal, actuando como factor garante de la extracción tributaria. La agregación del espacio fiscal al corregimiento y, de esta manera, anudado al conjunto de funciones propias de sus oficiales reales, es confirmada por la

\footnotetext{
${ }^{28}$ CLAVERO, 1982-1983, 95-167.

${ }^{29}$ SOLINIS ESTALLO, 2003.

${ }^{30}$ Las tercias reales se constituyen a partir de asumir en el esquema impositivo la tradicional división territorial de la diócesis de Burgos en arcedianatos. Tienen una fecha precisa: 1480, momento en el cual, con las Cortes de Toledo culminan la absorción de los "arcedianatos" por parte de las "merindades". Ello determina que las "tercias", enmarcadas anteriormente en la administración diocesana, pasaran a formar parte de la recaudación alcabalatoria desligándola, por ende, de la tutela eclesiástica e incorporando su cobro a la jurisdicción regia.

${ }^{31}$ Corresponde al Ordenamiento de 1338, dictado por Alfonso XI, estableciendo la regulación de la comercialización de la sal en la Corona de Castilla y declarando la propiedad real sobre las salinas y, fundamentalmente, el establecimiento de los lugares de importación de sal por vía marítima y la distribución de esta por vía del monopolio, los llamados alfolíes o salines reales. Véase LADERO QUESADA, 1973.

32 Como queda expresado en la propia documentación cuando se arrienden en forma conjunta "(...) la restitución de nuestro real patrimonio (...) alcabalas e tercias y salín de la villa de Santander e de la villa de San Vicente y sus tierras que son en la merindad de Asturias de Santillana con los lugares de Val de Toranzo que son en la dicha merindad realengos (...) e de las alcabalas e tercias de las villas de Castro de Urdiales e Laredo e sus tierras que son en la dicha merindad de Castilla Vieja”. A.G.S, Escribanía Mayor de Rentas, leg. 28, doc. 63.
} 
propia documentación. Se advierte, por ejemplo, en el poder emitido por el corregidor Carlos Enríquez de Cisneros el 15 de noviembre de 1502, en la cesión:

“(...) de la vara del oficio de la alcaldía e juzgado e justicia en la villa de San Vicente de la Barquera (...) se añade, a los habituales desempeños de justicia propias del cargo del teniente corregidor el de (...) recibir todos e cualesquier maravedíes de las alcabalas o encabezamientos de la dicha villa." 33

Sin embargo, es necesario que resaltemos otra dimensión que atañe directamente a pensar la propia constitución de un ámbito fiscal continuo en el Partido de las Cuatro Villas, y en este punto nos referimos a las particularidades propias que adquiere el sistema de arrendamiento de la alcabala. En tanto, si bien su titularidad es eminentemente patrimonio real, por otro lado, la gestión recaudatoria se encuentra "garantizada" a través de las propias familias poderosas locales. Hacia el siglo XV, la Hacienda Regia contaba con sus instituciones referentes, la Contaduría Mayor y la Escribanía Mayor de Rentas que, junto con el Rey, constituían la cabeza del sistema. A pesar de ello la presencia territorial debe ser garantizada en el dilatado espacio del reino de Castilla a través de recaudadores instalados en las distintas jurisdicciones fiscales. Esta red de agentes de recaudación se ampliaba a través de la figura de los "recaudadores e arrendadores" que, ajena en sí a la estructura administrativa propiamente dicha, permitirá a la Hacienda Regia obtener la cuota tributaria de personas distintas a aquéllas que la ley grava. ${ }^{34}$ Lo que importa señalar aquí, es la posibilidad de participación como licitadores, prestamistas y garantías de arriendo de familias enriquecidas que al amparo del dinero fácil participaban dentro del sistema de pujas y licitaciones abiertas en los remates. ${ }^{35} \mathrm{Si}$ ponemos en consideración el hecho de los frecuentes "traspasos" o "traspasamientos" (por los cuales el arrendador sin perder la titularidad sobre el uso de la renta cede la responsabilidad de la labor recaudatoria sobre una circunscripción) tenemos un sistema de relaciones que involucra como agentes de mayor significación las figuras del arrendador, del o de los fiador(es) y a los subalternos, es decir, una reducida compañía de arrendadores.

\section{Articulación territorial, corona y gobiernos locales}

En esta sintética descripción hemos intentado mostrar los elementos expansivos con los que cuenta la jurisdicción real sobre el conjunto de espacios jurisdiccionales locales y estamentales en la temprana modernidad. Se ha contextualizado, someramente, algunos de los elementos que partiendo de las ideas articuladoras del rey-iustum / rey-fiscus otorgan sentido al conjunto de instituciones y oficiales que participan en el entramado agregativo de los espacios locales en torno a la constitución del corregimiento y el corregidor. Es decir, alcanzamos el fenómeno desde su vértice, y en función del verdadero garante, que es el propio rey y sus agentes en las ciudades. ${ }^{36}$

\footnotetext{
33 A.G.S, Escribanía Mayor de Rentas, leg. 696.

${ }^{34}$ Como señala ARTOLA, 1982, 15-21. Hay que reconocer a esta forma de imposición tributaria no por su destinatario directo, el arrendador, sino en función de la autoridad que lo impone y le da sentido, en ese aspecto la Hacienda Regia es el principal acreedor de estas.

35 Véanse los trabajos de SOLINIS ESTALLO, 1994. Del mismo autor: 1992, 803-820.

${ }^{36}$ Con el fin de dimensionar la importancia que adquiere la figura del corregidor para la protección de los intereses de las villas frente a otros espacios señoriales podemos ilustrarlo a través de la carta enviada por el bachiller de Carranza a la reina en 1513, en cuanto a la situación en San Vicente de la Barquera: “(...) que la dicha villa e su tierra (...) es corregimiento sobre sí. Y vuestra alteza le dividió e apartó del corregimiento de las otras Tres Villas de la Costa de la Mar, a causa de que la dicha villa de San Vicente e su tierra está muy apartada de las otras villas de la costa (...). E por la mucha necesidad que la dicha villa de San Vicente tiene de corregidor, que de continuo resida en ella, porque está cercada de lugares de señorío
} 
De la misma forma, se ha destacado que a la consolidación del espacio jurisdiccional se le debe agregar la articulación -en paralelo- del espacio fiscal. Ambos elementos convergen temporalmente, a finales del siglo $\mathrm{XV}$, en la estructuración temprana del corregimiento y la importancia que adquiere la figura del corregidor a partir del fortalecimiento del rol articulador que cumplen las villas marítimas de la costa cantábrica. De esta manera, podemos afirmar que el fortalecimiento del corregidor va en concordancia a la afirmación y fortalecimiento del poder jurisdiccional de estos gobiernos urbanos en sus respectivos espacios de control local.

En este sentido, es interesante componer el diálogo entre estos agentes. Por un lado, el corregidor -representante de la corona-, por el otro, los regidores -miembros representativos de la corporación urbana-. Hacia el siglo XVI, era claro que jurídica y doctrinalmente el gobierno de las ciudades estaba a cargo de dos figuras. ${ }^{37}$ Dentro de los principios orgánicos de la representación de tipo antiguo régimen, tanto el corregidor como como los regidores personificaban a las corporaciones natural y jerárquicamente organizadas: la primera a la corona, los segundos al conjunto de la ciudad. Pero ambos lo hacían en forma disímil, ya que el corregidor era un oficio real ${ }^{38}$-se realizaba individualmente- en cambio, los regidores, formaban una corporación -el regimiento- un señorío colectivo que se identificaba con la propia ciudad a través de la elección en las regidurías de la "(...) mejor parte" de la misma, es decir, de su patriciado.

Es claro que, en este sentido, la potestad del regimiento de generar marcos normativos internos se centra en cuestiones propias de cada una de las villas, temas que tienen que ver con el gobierno propio de la villa, la organización de las elecciones, los asuntos económicos y la hacienda pública de la misma, la sanidad, el mercado, etc., materias -todas ellas- de las cuales el regimiento tiene plena capacidad de ordenamiento, según dispone la específica legislación del reino. Es que el "bien público" visto como propio de toda comunidad política organizada se cristaliza en estas regulaciones a partir de la potestad disciplinaría articulada en el regimiento y representada en la propia capacidad sancionatoria hacia los infractores a estos contenidos normativos. ${ }^{39}$ Estos marcos jurídicos locales (ordenanzas) no eran una creación sui generis. Las mismas se encontraban profundamente arraigadas en el cuerpo político urbano en cuanto muchas de ellas son viejas costumbres puestas por escrito por las que se han regido los miembros de la comunidad, lo que les otorga su legitimidad de base. La fuerza de estas formas ha sido observada muchas veces por parte de los historiadores como una resistencia del derecho local frente al territorial que patrocinaba la monarquía. Sin embargo, es mucho más factible entenderlas (doctrinalmente hablando) como un complemento ante la necesidad propia de toda comunidad política organizada de revitalizar la vigencia del contenido del viejo derecho local adaptándolo a las nuevas circunstancias sociales, económicas y

del Duque del Infantazgo, e Marqués de Aguilar, e otros caballeros (...).” A.G.S., Cámara de Castilla, Pueblos, leg. 17, doc. 383, fol. 1r.

${ }^{37}$ La doctrina política de la época partía de entender tanto la superioridad soberana del rey frente a una civitas (=comunidad política ordenada y perfecta) como también para aceptar la necesidad de autodeterminación normativa natural de la misma. En este sentido la propia teoría política de la época presuponía al propio Reino como "la asociación de diferentes ciudades". SUÁREZ, 1975, De Legibus. De civili potestate. III, i, 3, 9 .

${ }^{38}$ La descripción del corregidor como magistrado real es clara: "El corregidor es un magistrado y oficio real, que en los pueblos o provincias contiene en sí jurisdicción alta y baja, mero y mixto imperio, por el cual son despachados los negocios contenciosos, castigados los delitos y puestos en ejecución los actos de buena gobernación.” CASTILLO DE BOBADILLA, (1597 [1978]), Vol. I, Lib. I, Cap. II, 15-18.

${ }^{39} \mathrm{La}$ capacidad sancionatoria se establece a través de penas, que según los diversos colectivos urbanos pueden ser monetarias o en especie, o también condenatorias a penas de privación de libertad, a las que se pueden agregar el destierro, así como penas corporales o de escarnio público. 
políticas de unas ciudades y villas en permanente evolución. ${ }^{40}$ Por ejemplo, si tomamos el Libro de las Ordenanzas de la Villa marítima de Castro Urdiales ${ }^{41}$-en su morfología interna- la complementariedad existente entre el derecho municipal con las otras fuentes de derecho es manifiesta: junto con las ordenanzas de la villa figuran autos o capítulos de buen gobierno, disposiciones, etc., dictadas por el corregidor, su teniente o el alcalde mayor o juez de residencia que, a diferencia de las ordenanzas del concejo, son disposiciones que aparecen elaboradas unilateralmente por las autoridades y justicias, y cuya fuerza normativa alcanza a los vecinos y habitantes de la villa y de la jurisdicción que la misma encabeza. Sin embargo, es posible observar que los momentos en que estos "autos de buen gobierno" eran impuestos unilateralmente por parte de las justicias reales, tienen un objetivo preciso y delimitado, que en el caso que mencionamos de la Villa de Castro Urdiales, registra dos vertientes muy puntuales de intervención del corregidor: por un lado, aquellas tendientes a la pacificación en las disputas entre los linajes banderizados al interior del recinto amurallado ${ }^{42}$, y por el otro, aquellas que tienden a "corregir" abusos permanentes por gastos excesivos por parte de las autoridades concejiles. ${ }^{43}$ Ambas imágenes nos permiten reconocer la complementariedad con que se pondera doctrinalmente - la actuación del gobierno urbano consolidado en la dupla corregidor / regidores. Como vemos, en estos casos, la acción del corregidor era reparatoria del orden al interior del recinto urbano, interviniendo e imponiendo su autoridad como delegado regio frente a los posibles abusos y tensiones que surgieran de y entre los cuerpos políticos que formaban el conjunto de la villa.

Sin embargo, más allá de cualquier posición doctrinal al respecto, en la práctica, la acción de los corregidores se encontraba determinada también por las fluctuaciones propias de la política monárquica y la relación entre la corona y las villas cántabras no estuvo exenta de momentos de tensión. La inestable situación de la monarquía castellana durante el siglo XV conllevó -en varias oportunidades- a la "resistencia" de estos marcos urbanos a las disposiciones emitidas por la propia corona. Un ejemplo claro de ello es la disputa sostenida entre Diego Hurtado de Mendoza y la villa de Santander entre los años 1440-1467. Las tensiones en el espacio jurisdiccional de la Merindad de las Asturias de Santillana se acentuaron desde 1445, momento en el cual este territorio señorial se convertía en el Marquesado de Santillana con Íñigo López de Mendoza a la cabeza. El fortalecimiento político de dicho representante de la alta nobleza castellana se debe al apoyo ofrecido por la facción nobiliaria de los Mendoza al rey Enrique IV quien, con su ayuda, logró sortear con éxito la llamada "farsa de Ávila". En reconocimiento a sus servicios, el monarca concedió a los Mendoza la villa de Santander, colindante a su

\footnotetext{
40 Ante la imposibilidad de existencia de un derecho general abstracto y, por lo tanto, abarcativo del conjunto de los cuerpos que conforman el reino, el derecho territorial se ve complementado por los diferentes derechos locales.

${ }^{41}$ BARÓ PAZOS y GALVÁN RIVERO, op., cit.

${ }^{42}$ La pacificación de estos espacios urbanos es uno de los ejes de acción de gobierno de estos agentes reales. Ello queda ejemplificado en el pedido de informes cursado por los Reyes Católicos al corregidor de las Cuatro Villas de la Costa de la Mar de Castilla en noviembre de 1493, con el fin de informar sobre las redes de clientelismo generadas por los linajes urbanos: "En las Cuatro Villas del dicho corregimiento ay linajes y bandos... que son todos los vecinos principales de los pueblos (...) y de haber parientes mayores que tengan allegados de cuyo bando se llaman los menores de esas dichas villas (...) dicen que se han acrecido grandes males e muertes seguras, robos, salteamientos, quemas, fuerzas e las personas que los tales crimines e delitos cometen dicen que lo hacen con fuerza de los parientes mayores e de sus casas (...)" A.G.S., Registro General del Sello, vol. X, fol., 42; 1493, 11, 30.

${ }^{43}$ Como ejemplo, la inspección de cuentas realizada por el corregidor Diego de Soto el año de 1558. Éste determinó la elaboración del auto de buen gobierno “(...) para la buena gobernación y menos gastos de esta villa de Castro Urdiales (...)" El mismo entendía sobre la necesidad de bajar los gastos excesivos de los cuales disfrutaban los miembros del concejo. Ibídem. fol. 96r, 294.
} 
Marquesado. ${ }^{44}$ Dicha situación alteraba el precario equilibrio de poder y sometía a la dependencia señorial a la villa santanderina, y fue definida por los representantes de la ciudad como un "abuso" por parte del rey, al desgajar su dependencia del realengo y entregarla a los Mendoza. Según nos cuenta Lope García de Salazar, en las Bienandanzas e Fortunas, ${ }^{45}$ tres miembros del patriciado santanderino apoyaron las pretensiones del Marqués: Ferrand Sánchez de Alvarado, Juan Gutiérrez del Vear y Gonzalo de Solórzano, según el cronista banderizo "por dineros e vasallos que les daba por ello."46 La "traición" llevó al enfrentamiento armado en las calles de la ciudad entre las fuerzas de uno y otro bando. Lo interesante de señalar es que en el enfrentamiento la villa no estuvo sola, contó con el apoyo de los vecinos de otras villas costeras del realengo, desde San Vicente hasta Guipúzcoa:

“(...) e vino casi toda Trasmiera e Giles e Negretes (bandos linajes principales) en favor de la dicha villa, e aun de toda la costa fasta Fontarravía, pensándoles porque tal villa se partía de la Corona Real. E peleando cada día murieron muchos omes de todos (...) E los de Santander juntáronse muchas gentes e pusieron navíos por la mar e vinieron en su socorro Juan Alonso de Múgica con todos sus parientes e Gonzalo de Salazar, fijo de Lope Garçía, e Juan de Agüero e otros muchos de las villas de la costa..."47

Lo destacado no es el hecho de la resistencia de la villa a la decisión del propio monarca de enajenar su jurisdicción sobre ella. En sí, dicha situación se encontraba plenamente legalizada por la propia jurisprudencia regia. ${ }^{48} \mathrm{El} \mathrm{hecho} \mathrm{destacable} \mathrm{es} \mathrm{el} \mathrm{grado}$ de movilización colectiva lograda sobre el conjunto de villas y lugares que acuden al "auxilio" militar de Santander, dentro de la lógica de la propia defensa de sus derechos, ya que con dicha acción defendían la integridad del propio realengo. En este sentido las villas no consentirían ninguna apropiación del patrimonio regio por parte de la nobleza y su demostración de fuerza era clara, tanto para la alta nobleza del reino como para el propio monarca. Es decir, en este espacio amplio tendido entre el acatamiento y la resistencia se construye la relación entre la monarquía y los espacios locales. No es una relación directa de "acatamiento" sin más a los dictados de la corona, sino un juego de intereses y pactos siempre presentes, donde el agente real -el corregidor- debe moverse en función de lograr acuerdos permanentes para sostener la paz pública. Esta es otra dimensión del "buen gobierno de las villas".

Dicha función correctiva y de mediación configura un elemento central obrante en la propia acción del corregidor frente a los constantes conflictos, resistencias y pujas jurisdiccionales surgidas no solo con la alta aristocracia, sino también, entre las propias villas marítimas, así como sus aldeas y lugares adscritos a su término. Un caso ejemplificador de dichas tensiones lo vemos reflejado en la propia villa de Laredo con la aldea de Liendo (a finales del siglo XV) por la disputa jurisdiccional sobre el monte Candina, una importante reserva forestal que conformaba un paso natural que unía Oriñón con Liendo, y la cual Laredo se interesaba en controlar. El disparador del conflicto fue la visita realizada por el bachiller Cristóbal de Benavente -teniente corregidor en la villa-

\footnotetext{
${ }^{44}$ Véase para el desarrollo de los pormenores de este conflicto a PÉREZ BUSTAMANTE, 1975.

${ }^{45}$ GARCÍA DE SALAZAR, 1492 (1999).

46 Ibídem. Libro XXV, 1025.

${ }^{47}$ Ibídem, 1026.

${ }^{48}$ Real Academia de la Historia. Cortes de los antiguos reinos de León y de Castilla. Madrid, 1866-1, III, 394-401. "E que la tal cibdad o villa o logar que así fuere enajenada contra el tenor e forma de los suso dicho que pueda rresistyr e rresista syn pena alguna de fecho e de derecho a la tal alienación." Véase AÑIBARRO RODRÍGUEZ, 2013, 137.
} 
comisionado por Laredo para visitar el monte. ${ }^{49}$ Alertados los vecinos de Liendo por uno de sus vecinos llamado Pedro Resillo, repicaron las campanas convocando a otros hombres armados con el objetivo de matar a Benavente y tomar presos a los vecinos de Laredo que le acompañaban. Frente a estas tensiones el corregidor Juan de Deza ordenó realizar una pesquisa para averiguar lo sucedido y castigar a los culpables. La aldea de Liendo no pudo mantener los costes del proceso, pero tampoco abandonó su posición. Al año siguiente de 1497, con la llegada del nuevo corregidor Mosén Fernando de Rebolledo, solicitan abrir un juicio de residencia a Juan de Deza, en virtud de los "males" que éste había infligido a su aldea. ${ }^{50}$

Como vemos, la imposición de justicia por parte del corregidor servía de "obturador" de este tipo de disputas, pero no sin costo personal, inclinar el fiel de la balanza para una de las partes necesariamente significaba malquistar su posición respecto a alguno de los grupos en pugna.

\section{Conclusiones}

Hemos tomado como ejemplo solamente algunos conflictos puntuales que tienen como epicentro las cuatro villas marítimas cántabras, que se destacaban al interior del llamado corregimiento de las Cuatro Villas de la costa de la Mar tratando de ejemplificar la centralidad que adquieren las mismas en la constitución y articulación del área jurisdiccional amplia y el lugar que ocupa el propio corregidor como agente delegado del rey en este ordenamiento, así como su relación con los distintos espacios locales.

Como se ha podido observar, la relación entre los conglomerados locales englobados en el corregimiento no descansa en una sumisión automática por parte de los regimientos urbanos a la acción disciplinante y los dictados de la monarquía, sino más bien, en una construcción de acuerdos y compromisos -mutuamente limitados- no exentos de momentos de resistencia por parte de los poderes locales. Dicha conflictividad perenne en el espacio septentrional determina, en gran medida, la forma y dinámica que adquiere el proceso de agregación jurisdiccional desde la Edad Media en adelante. La consolidación de las villas marítimas, el fortalecimiento como espacios económicos y políticos determina la articulación del realengo, incorporando -lenta y trabajosamente- a su control jurisdiccional otras villas, aldeas y lugares.

El otorgamiento del fuero a las villas solo determina la demarcación de un ámbito de explotación. La construcción de un control efectivo del mismo supondrá, necesariamente, un desarrollo plagado de resistencias, de idas y vueltas, de pleitos y enfrentamientos (como hemos visto muchas veces, armados) confrontando a las propias aldeas incorporadas a sus términos, o entre las villas portuarias, a fin de consolidar sus derechos y límites, o contra la poderosa aristocracia castellana y vizcaína (deseosa de controlar estos importantes enclaves portuarios) y aún, contra la propia política monárquica.

Los avatares a los que la corona se hallaba sujeta con anterioridad a los Reyes Católicos hacían de estos espacios urbanos un codiciado premio a los servicios otorgados

\footnotetext{
49 A.G.S., Registro General del Sello. Diciembre 1496, fol. 300, “(...) yendo el bachiller procurador de Benavente, teniente de nuestro corregidor de la dicha villa a visitar los términos de ella e que al [ilegible] de la dicha visitación para visitar los términos que dicen del monte de Candina e que estando los visitando [ilegible] Pedro Resillo vecino del Valle de Liendo gran alboroto e escandalo dio muchas voces y perturbo desde un cerro llamando a los vecinos de Liendo (...) con muchas boses e saliendo e a repique de campana dicen que salieron hasta doce vecinos e ocho armados e dice que matasen al dicho Benavente."

${ }^{50}$ A.G.S., Registro General del Sello. Enero 1497, fol. 198; A.G.S., Registro General del Sello. Junio 1497, 179.
} 
a la alta nobleza, etc. A pesar, y frente a todo ello, las propias villas portuarias fueron conformando así su identidad y, al mismo tiempo, convirtiéndose en la cabeza de un espacio político y administrativo mucho más amplio, articulado en torno al llamado corregimiento de las Cuatro Villas de la Costa de la Mar de Castilla.

\section{REFERENCIAS BIBLIOGRÁFICAS}

AÑIBARRO RODRÍGUEZ, Javier, Las Cuatro Villas de la Costa de la Mar en la Edad Media. Conflictos Jurisdiccionales y Comerciales, Santander, Universidad de Cantabria, 2013.

ARIZAGA BOLUMBURU, Beatriz, "Conflictividad por la jurisdicción marítima fluvial en el Cantábrico en la Edad Media", en Ciudades y villas portuarias del Atlántico en la Edad Media. Logroño, Instituto de Estudios Riojanos, 2005, 17-55.

ARTOLA, Miguel, La Hacienda del Antiguo Régimen. Madrid, Alianza, 1982.

BARÓ PAZOS, Juan, Los hitos de un histórico conflicto territorial entre Cantabria y el País Vasco: el caso de Agüera (Guriezo) y Trucios: desde sus orígenes (Siglo XVI) hasta la sentencia del Tribunal Supremo de 9 de abril de 2008. Santander, Gobierno de Cantabria, 2010.

BARÓ PAZOS, Juan y GALVÁN RIVERO, Carmen, Libro de Ordenanzas de la Villa de Castro Urdiales (1519-1572). Santander, Excmo. Ayuntamiento de Castro Urdiales y Universidad de Cantabria, 2006.

- El Fuero de Laredo en el octavo centenario de su concesión. Santander, Universidad de Cantabria y Ayuntamiento de Laredo, 2001.

BERMÚDEZ AZNAR, Agustín, El corregidor de Castilla durante la Baja Edad Media (13481474), Murcia, Universidad de Murcia, 1979.

BLANCO CAMPOS, Emma, et al., Documentación referente a Cantabria en el Archivo General de Simancas. Sección Cámara de Castilla (años 1483-1530), Santander, Fundación Marcelino Botín, 2005.

, Libro del Concejo (1494-1522) y documentos medievales del Archivo Municipal de Castro Urdiales, Santander, Fundación Marcelino Botín, 1996.

CARZOLIO, María Inés, "En los orígenes de la ciudadanía en Castilla. La identidad política del vecino durante los siglos XVI y XVII," Hispania, LXII/2, 211, 2002, 637-692.

, "Vecinos, comunidades de aldea y súbditos del Reino. Identidad política en la periferia castellana. Siglos XVI y XVII," Anales de HistoriaAntigua, Medieval y Moderna, 36, 2004, 269-292.

CASTILLO DE BOBADILLA, Política para corregidores y señores de vasallos. Edición de GONZÁLEZ ALONSO, Benjamín, Madrid, (1597), 1978.

CLAVERO, Bartolomé, "Hispania fiscus, persona ficta. Concepción del sujeto político en el ius commune moderno", Quaderni Florentini, 11 / 12, 1982-1983, 95-167.

, "La monarquía, el derecho y la justicia" en MARTíNEZ RUIZ, Enrique y DE PAZZIS PI, Magdalena (coords.) Instituciones de la España Moderna. Las Jurisdicciones. Madrid, Actas, 1996, Tomo 1, 15-38.

CERDA, José Manuel, "Leonor Plantagenet y la consolidación castellana durante el reinado de Alfonso VIII", Anuario de estudios medievales 42/2, 2012, 629-652.

CUÑAT CISCAR, Virginia, Documentación Medieval de la Villa de Laredo 1200-1500, Santander, Fundación Marcelino Botín, 1998.

DIÉZ DE SALAZAR FERNÁNDEZ, Luis Miguel y AYERBE SALAZAR, María Rosa, Juntas y Diputaciones de Guipúzcoa (1550-1553, Documentos), Bilbao, Diputación Foral de Guipúzcoa, 1990. 
FORTEA PÉREZ, José Ignacio, "Principios de gobierno urbano en la Castilla delsiglo XVI", en MARTÍNEZ RUIZ, Enrique (ed.) Madrid, Felipe II y las ciudades de la Monarquía. Vol., I, Poder y Dinero. Madrid, Actas, 2000, 261-308.

FRANCO SILVA, Alfonso, "Los condestables de Castilla y la renta de los diezmos de la mar", En la España Medieval, 12, 1989, 225-284.

GARCÍA DE SALAZAR, Lope, Edición de las Bienandanzas y Fortunas de Garcíade Salazar, en MARÍN SÁNCHEZ, Ana María (ed.), Memorabilia: boletín de literatura Sapiencial, 3, (1492 [1999]), versión electrónica http://parnaseo.uv.es/Lemir/Textos/ bienandanzas.

GARCÍA VALDEAVELLANO, Luis, Curso de Historia de las Instituciones. De losorígenes al final de la Edad Media, Madrid, Alianza Editorial, 1998.

GARCÍA DE CORTÁZAR, José Ángel, "Elementos de definición de los espacios de poder en la Edad Media" en DE LA IGLESIA DUARTE, José Ignacio y MARTÍN RODRÍGUEZ, José Luis, Los espacios de poder en la España medieval: XII Semana de Estudios Medievales, Nájera, del 30 de julio al 3 de agosto de 2001, Logroño, Instituto de Estudios Riojanos, 2002, 13-46.

GONZÁLEZ ALONSO, Benjamín, El corregidor castellano (1348-1808), Madrid, Instituto de Estudios Administrativos, 1970.

HERZOG, Tamar, "La vecindad: entre la condición formal y negociación continua. Reflexiones en torno a las categorías sociales y las redes personales", Anuario IEHS, 15, 2000, 23-131.

, Vecinos y extranjeros. Hacerse español en la Edad Moderna,

Madrid, Alianza Editorial, 2006. 